\title{
Kecerdasan Emosional, Dukungan Sosial dan Stres Kerja Dokter Residen di Rumah Sakit Umum Pusat H. Adam Malik
}

\author{
Emotional Intelligence, Social Support and Occupational \\ Stress at H. Adam Malik General Hospital \\ Rahma Afwina* \\ Fakultas Psikologi, Universitas Medan Area, Indonesia,
}

Diterima: Agustus 2019; Disetujui: Desember 2019; Dipublish: Desember 2019

*Coresponding Email: rahmaafwina@staff.uma.ac.id

\begin{abstract}
Abstrak
Tujuan penelitian ini untuk menguji hubungan kecerdasan emosional dan dukungan sosial dengan stres kerja pada dokter residen di Rumah Sakit Umum Pusat H. Adam Malik Medan. Pendekatan yang dipergunakan dalam penelitian ini adalah pendekatan kuantitatif korelasional. Subjek penelitian adalah dokter residen dari departemen bedah, obgyn, dan anestesi sebanyak 132 orang. Pengambilan sampel dalam penelitian ini dengan total sampling. Peneliti menggunakan tiga jenis skala yaitu skala stres kerja, skala kecerdasan emosional dan skala dukungan sosial. Adapun teknik analisis data yang digunakan dalam penelitian ini adalah analisis regresi berganda. Berdasarkan hasil analisis data diperoleh koefisien Freg $=9,682$ dimana $p<0,05$. Menunjukkan bahwa terdapat hubungan yang signifikan antara kecerdasan emosional dan dukungan sosial dengan stres kerja pada dokter residen di Rumah Sakit Umum Pusat H. Adam Malik Medan. Variabel kecerdasan emosional dengan stres kerja memiliki nilai sebesar -0,184 dengan nilai $\mathrm{p}<0,05$, artinya arah hubungan variabel negatif yaitu semakin tinggi kecerdasan emosional akan semakin rendah stres kerja. Kemudian, variabel dukungan social dengan stres kerja memiliki nilai sebesar $-0,268$ dengan $\mathrm{p}<0,05$, artinya arah hubungan kedua variabel negatif, artinya semakin tinggi dukungan sosial akan semakin rendah stres kerja.
\end{abstract}

Kata kunci: Stres Kerja, Kecerdasan Emosional, Dukungan Sosial.

\begin{abstract}
The aim of this study is to investigated the relationship between emotional intelligence, social support and occupational stress at H. Adam Malik General Hospital Medan. The approach used to this study is quantitative correlational. The study participants were 132 of resident doctors of three departement: surgical, obgyn, and anesthesia. They were selected, making use of total sampling technique. The participants were administrated three questionnaires: emotional intelligence questionnaire, social support questionnaire, and occupational stress questionnaire. Multiple regression analysis was applied as a statistical test to analyze the data. According to results revealed coefficient $F_{\text {reg }}=9,682(p<0,05)$. The findings revealed that there was a significant relationship between emotional intelligence, social support and occupational stress at H. Adam Malik General Hospital Medan. The value of emotional intelligence and occupational stress amounts to $-0,184(p<0,05)$, it shows that as a emotional intelligence increase, occupational stress will decrease. Subsequently, The value of social support and occupational stress amounts to $-0,268(p<0,05)$, it shows that as a social support increases, occupational stress also will decrease.
\end{abstract}

Keywords: Emotional Intelligence, Social Support and Occupational Stress.

How to Cite: Afwina, R. (2019). Kecerdasan Emosional, Dukungan Sosial, dan Stres Kerja Dokter Residen di Rumah Sakit Umum Pusat H. Adam Malik. Journal of Education, Humaniora and Social Sciences (JEHSS). 2 (2): 229-236. 


\section{PENDAHULUAN}

Di dalam sistem organisasi rumah sakit, terdapat tiga kelompok kekuatan yang saling mendesak satu sama lain. Kelompok yang pertama adalah kelompok direksi dan staf direksi yang memiliki kekuatan berdasarkan pada legitimasi (Legitimating Power) sebagai penentu kebijakan operasional. Kelompok kedua adalah kelompok dokter spesialis, dokter umum dan dokter gigi yang memiliki kekuatan berdasarkan pada keahlian (Expertise Power). Kelompok ketiga adalah kelompok perawat dan para medis yang memiliki kekuatan berdasarkan pada jumlah yang paling besar di rumah sakit (Subanegara, 2005).

Residen atau dokter residen merupakan periode yang berisiko tinggi untuk mengalami masalah psikiatrik akibat stresor yang terkait dengan tugasnya. Dokter residen berhadapan dengan stresor yang berasal dari profesinya sendiri dan proses belajar dan mengajar, dimana hal-hal tersebut dapat membuat mereka stres (Demir, Pinar, Erbas, Ozdil \& Yasar, 2007). Pada tahap residensi, profesional ini hidup dalam situasi: kurang tidur, kelelahan, pelayanan yang terlau banyak, pekerjaan administratif yang berlebihan, masalah dengan kualitas pendidikan dan lingkungan pendidikan (Martin; dalam Silva, Goulart, C.T., Bolzan, Serrano \& Guido, 2013).

Residen diharapkan mampu memenuhi tuntutan klinis, akademis, fisis, dan sosial, sementara itu harus bekerja hingga 80 jam per minggu (Katz, Sharp \& Ferguson, 2006). Pada beberapa studi mengenai stres kerja dokter, tingkat stres kerja jauh lebih tinggi pada dokter residen daripada dokter senior (Kang, Kang, dkk, 2007; Kang, Kam, dkk, 2001; Jin, Kam, dkk, 2003). Dokter residen memiliki tingkat stres kerja yang tinggi yang mengarah kepada depresi yang disebabkan oleh berbagai faktor risiko. Oleh karena itu, penting untuk mengenali gejala awal stres kerja pada dokter residen, mendorong untuk mengungkapkan apa yang dirasakan, memberikan dukungan sosial dan membantu dokter residen untuk meningkatkan kemampuan mengatasi masalah (Kim, Lee \& Choi, 2015).

Berdasarkan hasil pengamatan peneliti terhadap seluruh departemen, terdapat tiga departemen yang menjadi perhatian peneliti, yaitu departemen bedah, departemen obgyn, dan departemen anestesi. Berdasarkan hasil wawancara singkat dan pengamatan peneliti terhadap dokter residen dari ketiga departemen tersebut, mereka mengatakan bahwa mereka lebih mudah tersinggung, berselisih dengan perawat karena selalu 
dianggap bukan tenaga medis yang memiliki wewenang untuk menangani pasien/mengambil tindakan untuk pasien, mereka disetarakan dengan koas, perawat juga menganggap mereka sebagai asisten. Kemudian, merasa cemas karena tanggung jawab mereka bukan hanya sebagai seorang dokter, namun juga pada pendidikan. Selain itu, rekan sejawat juga cukup sering membuat mereka kesal.

Sebuah tinjauan literatur mengenai kecerdasan emosional di lingkungan medis menunjukkan ada kaitan yang erat terhadap kecerdasan emosional pada profesi dokter, meliputi 6 kompetensi, yaitu Kemampuan Interpersonal dan Komunikasi, Perawatan Pasien, Profesionalisme, Pengetahuan Medis, Belajar dan Peningkatan Berbasis Praktek. Oleh sebab itu, mengenali dan mengelola emosi adalah hal yang paling mendasar pada profesi dokter (Arora, Russ, Petrides, Sirimanna, Aggarwal, Darzi \& Sevdalis, 2011).

Selain kecerdasan emosional, menurut Taylor (2005), faktor lain yang juga dapat mempengaruhi stres kerja yaitu dukungan sosial. Taylor mengemuakakan bahwa dukungan sosial dapat menurunkan dampak stres. Ketika menghadapi peristiwaperistiwa yang penuh tekanan, individu membutuhkan dukungan sosial. Individu yang memperoleh banyak dukungan sosial tidak hanya mengalami stres yang rendah, tetapi juga dapat mengatasi stres lebih efektif dibandingkan dengan individu yang kurang memperoleh dukungan sosial. Taylor juga menambahkan bahwa dukungan sosial menjadi pelindung kondisi psikologis seseorang akibat stres.

Lebih jauh, House \& Kahn (1985) mengemukakan bahwa dukungan sosial dapat mengurangi stres di tempat kerja. Kuantitas dan kualitas hubungan sosial individu dengan pasangan hidup, rekan kerja, atasan berpengaruh pada kemampuan individu dalam menanggulangi stres yang dihadapi. Luthan (2010) juga menyebutkan bahwa karyawan sangat dipengaruhi oleh dukungan dari satu atau lebih anggota kelompok. Dengan berbagai masalah dan kegembiraan dengan orang lain, individu akan merasa lebih baik. Jika seseorang karyawan kurang memperoleh dukungan sosial ini, situasi yang timbul adalah situasi yang penuh stres.

Dari beberapa uraian dan penjelasan diatas, diasumsikan bahwa kecerdasan emosional dan dukungan sosial merupakan faktor-faktor yang dapat mempengaruhi terjadinya stres kerja. Keberhasilan individu dalam mengelola emosi akan membuat dokter menjadi lebih fokus dalam menjalankan tugas dan tanggung jawabnya. Kemudian, bersamaan dengan hal tersebut, dokter yang mendapatkan dukungan sosial akan dapat 
menjalankan tugasnya dengan lebih baik sehingga dapat meminimalkan efek stres. Sehingga berdasarkan itu maka peneliti ingin mengetahui lebih lanjut mengenai “Kecerdasan Emosional, Dukungan Sosial, dan Stres Kerja pada Dokter Residen di RSUP H. Adam Malik Medan".

\section{METODE PENELITIAN}

Penelitian ini dilaksanakan pada Rumah Sakit H. Adam Malik Medan, Jl. Bunga Lau No. 17 Medan. Pelaksanaan penelitian dilakukan pada bulan Februari sampai dengan Maret 2016. Variabel-variabel yang digunakan dalam penelitian ini adalah: Variabel terikat (dependent), yaitu stres kerja dokter residen dan Variabel bebas (independent), meliputi: Kecerdasan Emosional dan Dukungan sosial

Penelitian ini dilakukan pada dokter residen yang berasal dari departemen bedah, departemen obgyn, dan departemen anestesi di Rumah Sakit Umum Pusat H. Adam Malik Medan sebagai populasi penelitian. Teknik pengambilan sampel yang digunakan dalam penelitian ini adalah total sampling yaitu teknik penentuan sampel dengan mengambil seluruh anggota populasi sebagai responden atau sampel. Dengan demikian maka peneliti mengambil sampel dari seluruh dokter residen bedah, anestesi dan obgyn di Rumah Sakit Umum Pusat H. Adam Malik Medan yang berjumlah 132 orang.

Metode yang akan digunakan untuk mengumpulkan data pada penelitian ini adalah metode kuantitatif dengan skala psikologi sebagai alat pengumpulan data. Skala psikologi berisi sekumpulan pernyataan atau pertanyaan tertulis untuk dijawab secara tertulis oleh responden penelitian.

Respon jawaban dalam skala penelitian ini menggunakan 4 (empat) pilihan, yaitu Sangat Setuju (SS), Setuju (S), Tidak Setuju (TS), Sangat Tidak Setuju (STS). Skor berkisar dari 4 sampai 1 , semakin tinggi nilai skor maka semakin tinggi tingkat stres kerja, kecerdasan emosional dan dukungan sosial.

Pada item favourable, pilihan SS mendapat skor 4, S mendapat skor 3, TS mendapat skor 2, dan STS mendapat skor 1. Pada item unfavourable, pilihan SS mendapat skor 1, S mendapat skor 2, S mendapat skor 3, dan STS mendapat skor 4. 


\section{HASIL DAN PEMBAHASAN}

Melihat hasil uji coba dari skala stres kerja dari 34 butir pernyataan, sebanyak 26 butir yang valid, untuk skala kecerdasan emosional, dari 30 butir pernyataan, sebanyak 23 butir yang valid, sedangkan skala dukungan sosial dari 22 butir pernyataan, sebanyak 17 butir yang valid. Namun dari 132 eksemplar skala yang dibagikan, terdapat 6 eksemplar skala yang tidak dikembalikan, yaitu 2 eksemplar dari dokter residen bedah, dan 4 eksemplar dari dokter residen obgyn. Sehingga jumlah skala yang dikembalikan kepada peneliti berjumlah sebanyak 126 eksemplar.

\section{Uji Asumsi}

\section{a. Uji Normalitas Sebaran}

Uji normalitas sebaran dianalisis dengan menggunakan Uji Kolmogorov - Smirnov. Sebagai kriterianya apabila p>0,050 maka sebarannya dinyatakan normal, sebaliknya apabila p<0,050 sebarannya dinyatakan tidak normal (Hadi dan Pamardiningsih, 2004). Tabel berikut ini merupakan rangkuman hasil perhitungan uji normalitas sebaran.

Tabel 1. Rangkuman hasil Perhitungan Uji Normalitas Sebaran

\begin{tabular}{|l|l|l|l|l|l|}
\hline Variabel & RERATA & SB & K-Z & P & Keterangan \\
\hline Stres Kerja & 55.26 & 7.604 & 1.268 & 0,80 & Normal \\
\hline Kecerdasan Emosional & 55.26 & 7.587 & 1.094 & .183 & Normal \\
\hline Dukungan Sosial & 42.41 & 6.930 & 1.142 & .147 & Normal \\
\hline Keterangan : & & & \\
RERATA Nilai rata-rata & & & \\
SB = Simpangan Baku (Standart Deviasi) & & & \\
p $\quad=$ Peluang Terjadinya Kesalahan & & & \\
K-Z Kolmogorov-Smirnov Z Test &
\end{tabular}

\section{b. Uji Linieritas Hubungan}

Uji linieritas dilakukan untuk mengetahui apakah hubungan antara kecerdasan emosional dan dukungan sosial dengan stres kerja linier atau tidak. Hasil uji linieritas dapat dilihat pada tabel berikut :

Tabel 2. Rangkuman Hasil Perhitungan Uji Linieritas Hubungan

\begin{tabular}{|c|c|c|c|}
\hline Korelasional & $\mathrm{F}$ & $\mathrm{p}$ & Keterangan \\
\hline $\mathrm{X}_{1-} \mathrm{Y}$ & 10.315 & 0,002 & Linier \\
\hline $\mathrm{X}_{2-} \mathrm{Y}$ & 14.180 & 0,009 & Linier \\
\hline \multicolumn{4}{|l|}{ Keterangan : } \\
\hline$=\mathrm{Kec}$ & \multicolumn{3}{|c|}{$=$ Kecerdasan Emosional } \\
\hline$=\mathrm{Dul}$ & \multicolumn{3}{|c|}{ = Dukungan Sosial } \\
\hline$=$ Str & \multicolumn{3}{|c|}{$=$ Stres Kerja } \\
\hline F Beda $=$ Ko $€$ & \multicolumn{3}{|c|}{$=$ Koefisien linieritas } \\
\hline p Beda = Pro & \multicolumn{3}{|c|}{$=$ Proporsi peluang terjadinya kesalahan } \\
\hline
\end{tabular}




\section{Analisis Regresi Berganda}

Tabel 1. Analisis Regresi Berganda

Coefficients $^{\mathrm{a}}$

\begin{tabular}{|c|c|c|c|c|c|c|c|c|}
\hline \multirow[t]{2}{*}{ Model } & \multicolumn{2}{|c|}{$\begin{array}{c}\text { Unstandardized } \\
\text { Coefficients }\end{array}$} & \begin{tabular}{|c|} 
Standardized \\
Coefficients \\
\end{tabular} & \multirow[t]{2}{*}{$\mathrm{t}$} & \multirow[t]{2}{*}{ Sig. } & \multicolumn{3}{|c|}{ Correlations } \\
\hline & $\mathrm{B}$ & Std. Error & Beta & & & Zero-order & Partial & Part \\
\hline (Constant) & 80.054 & 6.100 & & 13.124 & .000 & & & \\
\hline 1 Kecerdasan_Emosional & -.183 & .088 & -.183 & -2.081 & .040 & -.263 & -.184 & -.174 \\
\hline Dukungan_Sosial & -.297 & .096 & -.271 & -3.090 & .002 & -.325 & -.268 & -.259 \\
\hline
\end{tabular}

a. Dependent Variable: Stress_Kerja

$$
\begin{array}{ll}
\text { Keterangan : } \\
\text { RERATA } & =\text { Nilai rata-rata } \\
\mathrm{SB} & =\text { Simpangan Baku (Standart Deviasi) } \\
\mathrm{p} & =\text { Peluang Terjadinya Kesalahan } \\
\mathrm{K}-\mathrm{Z} & =\text { Kolmogorov-Smirnov Z Test }
\end{array}
$$

\begin{tabular}{|c|c|c|c|c|c|}
\hline Model & Sum of Squares & $\mathrm{df}$ & $\begin{array}{l}\text { Mean } \\
\text { Square }\end{array}$ & $F$ & Sig. \\
\hline $\begin{array}{l}\text { Regression } \\
\text { Residual } \\
\text { Total }\end{array}$ & $\begin{array}{l}983.160 \\
6245.197 \\
7228.357\end{array}$ & $\begin{array}{l}2 \\
123 \\
125\end{array}$ & $\begin{array}{l}491.580 \\
50.774\end{array}$ & 9.682 & $.000^{b}$ \\
\hline
\end{tabular}

Tabel 2. Tabel Analisis regresi secara bersama-sama

a. Dependent Variable: Stress_Kerja

b. Predictors: (Constant), Dukungan_Sosial, Kecerdasan_Emosional

\section{Koefisien Determinasi}

Koefisien determinasi digunakan untuk menjelaskan proporsi variabel terikat yang mampu dijelaskan oleh variasi variabel bebasnya. Nilai koefisien determinasi adalah $0<$ $\mathrm{R}^{2}<1$. Nilai $\mathrm{R}^{2}$ yang kecil berarti kemampuan variabel bebas dalam menjelaskan variabel terikat sangat terbatas. Nilai yang mendekati satu berarti variabel bebas memberikan hampir semua informasi yang dibutuhkan untuk memprediksi variabel terikat (Ghozali, 2011).

Hasil analisis data dalam penelitian ini menunjukkan koefisien determinan $\left(\mathrm{R}^{2}\right)$ dari hubungan antara kecerdasan emosional dan dukungan sosial dengan stres kerja akademik adalah sebesar 0,136. Hal ini berarti kontribusi efektif Kecerdasan Emosional dan Dukungan Sosial dalam menurunkan Stres Kerja adalah sebesar 13,6\%.

\section{Hasil Perhitungan Mean Hipotetik dan Mean Empirik}

Besarnya mean hipotetik (Mean teoritik) dan standart deviasi $(\sigma)$ dihitung dengan mendasarkan pada jumlah aitem yang valid, skor maksimal serta skor minimal pada 2.34n http://mahesainstitute.web.id/ojs2/index.php/jehss 
masing-masing alternatif jawaban. Guna memudahkan dalam interprestasi data kemudian dilakukan kategorisasi. Kategorisasi dilakukan dengan menggunakan model distribusi normal (Azwar, 2015).

Tabel 3. Hasil Perhitungan Nilai Rata-rata Hipotetik dan Nilai Rata-rata Empirik

\begin{tabular}{|l|l|l|l|}
\hline \multirow{2}{*}{ VARIABEL } & \multicolumn{2}{|l|}{ NILAI RATA-RATA } & \multirow{2}{*}{ KETERANGAN } \\
\cline { 2 - 3 } & Hipotetik & Empirik & \\
\hline Stres Kerja & 65 & 55,26 & Rendah \\
\hline Kecerdasan Emosional & 57,5 & 66,56 & Tinggi \\
\hline Dukungan Sosial & 35 & 42,41 & Tinggi \\
\hline
\end{tabular}

\section{SIMPULAN}

Berdasarkan hasil penelitian, disimpulkan bahwa dokter residen yang memiliki kecerdasan emosional yang tinggi cenderung dapat menekan tingkat stres kerja, dokter residen yang memiliki dukungan sosial yang tinggi cenderung dapat menekan tingkat stres kerja, dokter residen yang memiliki kecerdasan emosional dan dukungan sosial yang tinggi cenderung dapat menekan tingkat stres kerja.

\section{DAFTAR PUSTAKA}

Arora, S., Russ, S., Petrides, K. V., Sirimanna, P., Aggarwal, R., Darzi, A., \& Sevdalis, N. (2011). Emotional Intelligence and stress In Medical Students Performing Surgical Tasks. Acad Med. Vol. 86, No.10, pp 1311-1317.

Azwar, S. (2015). Penyusunan Skala Psikologi. Yogyakarta: Pustaka Pelajar.

Demir F, Pinar AY, Erbas M, Ozdil M, Yasar E. (2007). The Prevalence of Depression and Its Associatied Factors Among Resident Doctors Working In a Training Hospital In Istanbul. Turk Psikiyatri Dergisi. Vol. 18, pp. 1-6.

Ghozali, I. (2011). Aplikasi Analisis Multivariate Dengan Program IBM SPSS19. Semarang: BP Universitas Diponegoro

Hadi, S \& Pamardiningssih, Y. (2004). Program Statistik SPS. Yogyakarta: UGM.

House, J. S, Kahn RL. (1985). Measures and Concepts Of Social Support. In: Cohen S, Syme SL, eds. Social Support and Health. New York: Academic Press.

Jin DG, Kam S, Kang YS, dkk. (2003). Professional Job Perception, Job Stress and Job Satisfaction Of Doctors Practicing In Local Clinic In Daegu City. Korean J Prev Med. Vol. 36, pp. 53-62.

Kang YS, Kam S, Lee SW, Chun BY, Yeh MH. (2001). Job Stress and Its Related Factors In South Korean Doctors. Korean J Prev Med. Vol. 34, pp. 141-148.

Kang MK, Kang YS, Kim JR, dkk. (2007). The Levels Of Psychosocial Stress, Job Stress and Related Factors Of Medical Doctors Practicing At Local Clinics. J Prev Med Public Health. Vol. 40, pp. 177-184.

Katz ED, Sharp L, Ferguson E. (2006). Depression Among Emergency Medicine Residents Over An Academic Year. Acad Emerg Med. Vol. 13, pp. 284-287.

Kim, K., Lee, S, \& Choi, Y.H. (2015). Relationship Between Occupational Stress and Depressive Mood Among Interns and Residents In A Tertiary Hospital, Seoul, Korea. Clin Exp Emerg Med. Vol. 2, No. 2, pp. 117-122.

Luthans, F. (2010). Organizational Behaviour. 12th Edition. International Edition. New York: McGraw Hill.

Silva, R.M., Goulart, C.T., Bolzan, Oliveira. M.E.O, Serrano, P.M., Lopes, L.F.D., Guido, L.A. (2013). Stress and Hardiness In Medical Residents. J Nurs UFPE. Vol. 7, No. 9, pp. 5406-5413. 
Rahma Afwina, Kecerdasan Emosional, Dukungan Sosial, dan Stres Kerja Dokter Residen di Rumah Sakit Umum Pusat

Subanegara, Hanna \& Permana, (2005). Diamond Head Drill \& Kepemimpinan dalam Manajemen Rumah Sakit. Yogyakarta: ANDI

Taylor, S.E. (2005). Social Psychology. 12th Edition. Practice Hall College Div. 